\title{
Genetic improvement and farming technological innovation on fleshy shrimp Fenneropenaeus chinensis in China
}

\section{Qingyin Wang*, Jian Li, Jie Kong, Jie Huang, Weiji Wang, Xianhong Meng and Yuying He}

Yellow Sea Fisheries Research Institute, Chinese Academy of Fishery Sciences, 106 Nanjing Road, Qingdao 266071, China

\begin{abstract}
The farming of the fleshy shrimp Fenneropenaeus chinensis, one of the indigenous and most important mariculture species in the coastal areas of Northern China, has experienced a dramatic fluctuation in the last two decades. The outbreak of white spot syndrome virus (WSSV) in 1993 resulted in a production collapse of this species; many efforts have been made to restore the industry thereafter. In order to improve the growth performance and disease resistance of shrimp, systematic selective breeding and technological innovation on farming practices were introduced. Two new varieties of $F$. chinensis, named "Huanghai No. 1" and "Huanghai No. 2" were developed after 7 and 10 years of selective breeding, respectively. The characteristic trait of "Huanghai No. 1" is faster growth. Compared with the unselected population, its average body length and body weight increased by $8.40 \%$ and $26.86 \%$ respectively. The new variety "Huanghai No. 2" was developed using a combined individual/family selection methods and the multi-trait BLUP (Best Linear Unbiased Prediction) strategy. This new variety was WSSV tolerant, as evidenced by higher survival rate and longer survival time after WSSV infection when compared to commercial seedling. Meanwhile, efforts were made to innovate and/or improve farming technologies to cope with the local shrimp farming conditions. Currently, the farming industry of $F$. chinensis in Northern China is recovering, and the farmers' confidence reveals a prosperous future for farming this shrimp species in Northern China, even though challenges still exist and much more efforts are needed for further development.
\end{abstract}

\section{Introduction}

The fleshy shrimp, F. chinensis, with its relatively big size, high quality meat, good taste and large market share, has played an important role in shrimp farming and fisheries in Northern China, especially in provinces along the coasts of Bohai Sea and Yellow Sea before 1995 (Deng 1997; Deng and Ye 2001). The natural distribution of this shrimp is confined to the Bohai Sea, Yellow Sea, East China Sea and a small area 
of the northern part of the South China Sea (Deng et al. 1990). Researches on the reproductive biology, larval rearing and farming technology of $F$. chinensis has been conducted since the 1950's in China. In the 1970's, a series of technical breakthroughs dramatically accelerated the development of shrimp farming industry. From the middle of the 1980s to the early 1990s, China was the world leader in terms of larval rearing and the scale of shrimp farming with a production area around 150,000 ha and an annual production of 200,000 tons (Wang et al. 1995). Shrimp farming had become one of the most important industries in the coastal areas for local economic development. Unfortunately, $F$. chinensis farming has declined since 1993 due to serious viral disease outbreaks caused by white spot syndrome virus (WSSV), which has resulted in a dramatic decrease of $F$. chinensis production (Huang et al. 1995c; Wang et al. 2006).

Systematic research was carried out to determine the causes of the WSSV outbreak and production decline. The factors that contributed to the decline of $F$. chinensis farming included: a) Lack of genetically improved shrimp stocks: From experience with crop and animal husbandry, developing genetically improved stocks with characteristics of faster growth rate and/or disease resistance (or tolerance) is a basic component of maintaining a sustainable and healthy shrimp farming industry; b) Available disease diagnosis techniques could not meet the needs of shrimp farming practices: There was still a lack of available early disease (WSSV) warning mechanisms with which farmers could take necessary measures as early as possible and reduce economic loss; c) Traditional larva rearing and pond farming technology could not control pathogen introduction and transmission: Research reports suggested that the natural seawater, with live food organisms such as rotifer and several other invertebrates that are involved in shrimp larval rearing and pond farming were all possible WSSV carriers (Lo et al. 1996; Zhang et al. 2006; Yan et al. 2007); d) Related techniques involved in farming practice needed urgent improvement.

The US Marine Shrimp Farming Consortium had developed specific pathogenfree (SPF) populations of Litopenaeus vannamei to provide healthy seed to commercial farmers (Carr et al. 1994; Pruder et al. 1995; Wyban et al. 1995) as a means to support aquaculture of the species in the United States since 1990's. In order to revitalize $F$. chinensis farming industry in China, systematic research has been carried out since the mid 1990's to mitigate the situation and meet the urgent needs of the shrimp farming industry including selective breeding, pathogen detection and disease control, new modes of shrimp farming and complementary technique development. Based on more than 10 years of efforts, two new varieties of $F$. chinensis named "Huanghai No.1" with a registration No. GS-01-001-2003 and "Huanghai No.2" with a registration No. GS-01-002-2008, respectively and new modes of shrimp farming tailored to the local conditions were developed ( $\mathrm{Li}$ et al. 2005; 2006a). With the full support from 
governmental agencies and shrimp farmers, the new varieties have been commercially cultured and new farming modes are practiced in the coastal areas of Northern China. A prosperous future for the fleshy shrimp $F$. chinensis farming is anticipated, even though challenges still exist and much more efforts are needed for further development. This paper provides an updated overview of $F$. chinensis breeding program and farming practices in China.

\section{Selective Breeding for Faster Growth-- "Huanghai No. 1".}

\section{Materials and Technical Approachesh}

Growth performance improvement is undoubtedly the first target in any shrimp selective breeding program, as it is a trait with significant economic impacts. Mass selection was carried out on $F$. chinensis to improve its growth rate from 1997 to 2004 . The initial population was selected from the wild catch in the Yellow Sea, where $F$. chinensis overwinter and migrate to the coastal waters to spawn. For each of the selected generations, usually over 5000 individuals were taken from ponds of different farming areas and transferred to overwintering tanks during late October to early November, after the shrimp completed their natural mating in farming ponds. By March of the next year, about 500 individuals were re-selected from the overwintered population and used as spawners to produce the next generation. During the re-selection process, individual shrimp was screened for WSSV infection using techniques such as T-E staining (Trypan blue-Eosin Y straining) (Huang et al. 1995a), ELISA with monoclonal antibody and/or dot blot test kit with gene probe (Huang et al. 1995b; Lei et al. 2001) and PCR technology. Only individuals with negative results were kept for spawning. Considering the large quantity of farmed shrimp from which the selection was made, an estimated selection intensity of 1 3\% was applied through the whole process of selective breeding. In addition to the traditional selective breeding techniques, modern molecular biotechnologies were applied to assist the selection which included random amplified polymorphic DNA(RAPD), simple sequence repeats (SSR) and amplified fragment length polymorphism (AFLP) technologies for genetic diversity assessment of selected population (He et al. 2004; Zhang et al. 2005; Li et al. 2006b), RAPD, SSR and AFLP for genetic linkage mapping construction (Li et al. 2006a; Liu et al. 2010), identifying two molecular markers associated with desired traits detection (He et al. 2007).

\section{Growth Performance in Selected Generations}

Selective breeding was conducted from 1997 2004. At the time of harvest, which was usually carried out in October in Shandong Province, random samplings 
were made from experimental ponds that belonged to the same farm with the same pond managements to evaluate the results in each generation (Table 1). The sampled data showed that in the second through to the fifth generation, the average body length of the selected populations increased steadily, and shrimp body length ranges also showed a trend of progressive increase.

The selected variety passed the appraisement of the National Certification Committee for Aquatic Varieties in the end of 2003 after seven generations' selection, and was named "Huanghai No. 1" with a registration No. GS-01-001-2003. It was the first new variety of $F$. chinensis ever genetically improved and also the first successfully artificially bred marine aquatic animal variety in China (Li et al. 2005) (Fig. 1). Since 2006, "Huanghai No 1" has been recommended by the Ministry of Agriculture of China to be cultured with priority in the coastal areas of China.

Table 1. Sampling data of $F$. chinensis at harvest of the second through fifth generation of selection.

\begin{tabular}{lcccc}
\hline Selected generation & Sampling date & $\begin{array}{c}\text { Sampling } \\
\text { No. }\end{array}$ & $\begin{array}{c}\text { Average body } \\
\text { length }(\mathrm{cm})\end{array}$ & $\begin{array}{c}\text { Range of body } \\
\text { length }(\mathrm{cm})\end{array}$ \\
\hline The 2nd generation & October 2 3, 1998 & $>300$ & 12.13 & $9.3-14.2$ \\
The 3rd generation & October 2 4, 1999 & $>300$ & 13.29 & $9.7-15.5$ \\
The 4th generation & October 3 5, 2000 & $>300$ & 13.59 & $11.0-16.4$ \\
The 5th generation & October 2 4, 2001 & $>300$ & 15.10 & $12.9-18.3$ \\
\hline
\end{tabular}

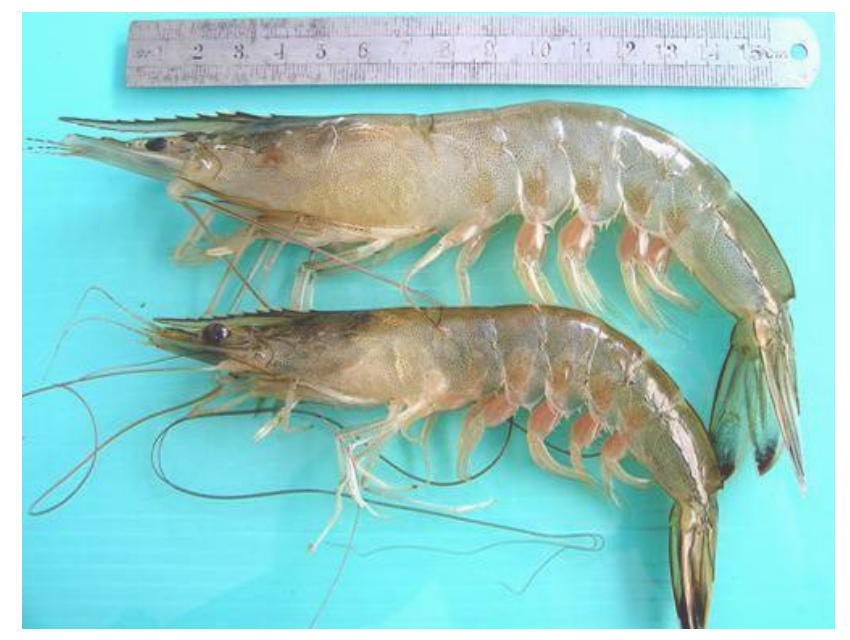

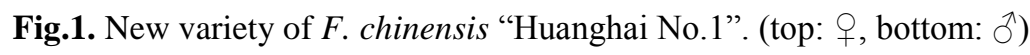




\section{Main Characteristics of "Huanghai No. 1"}

\section{Growth Rate and Morphology}

The first important characteristic of the new variety "Huanghai No. 1" was faster growth rate. Compared to the unselected population, the average body length of the new variety increased by $8.40 \%$ and the average body weight increased by $26.68 \%$ at the time of harvest (Li et al. 2005) (Fig. 2). This was based on the data collected from a dozen of experimental farming ponds during an appraisement by a group of renowned scientists working in this field.

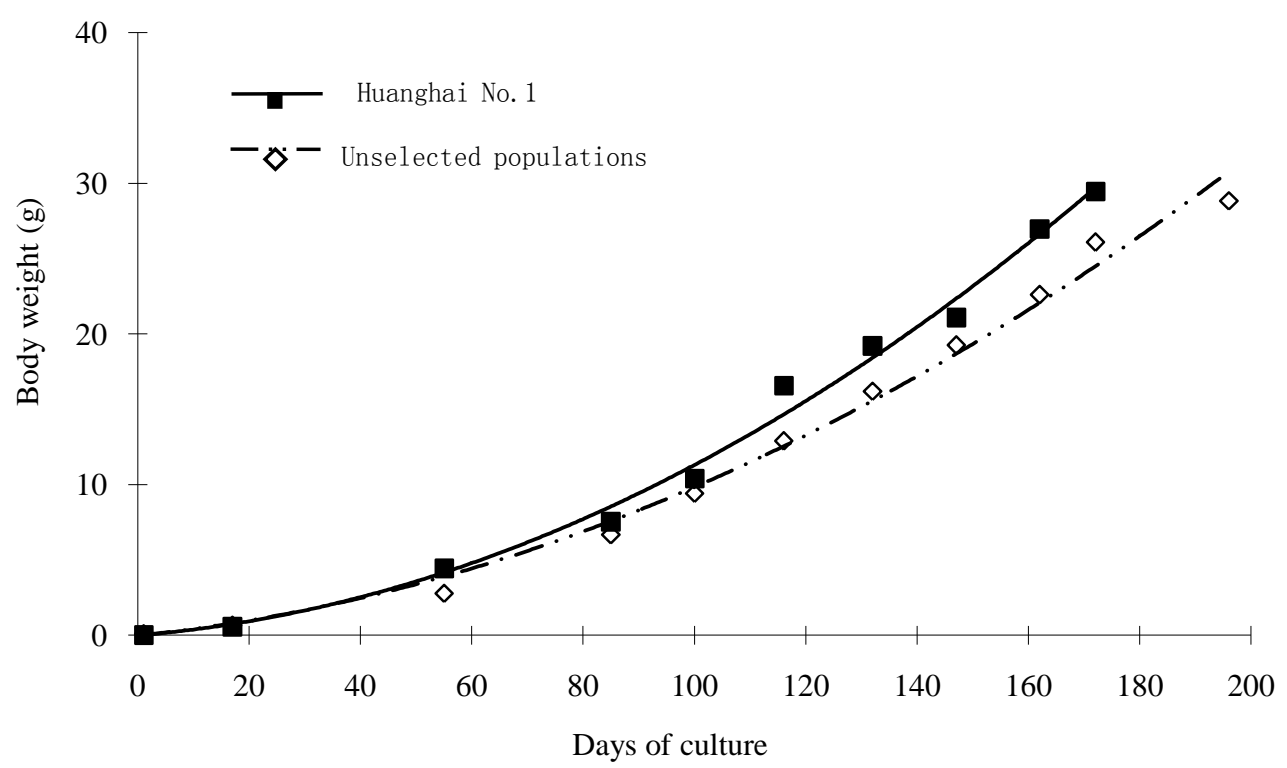

Fig. 2. Comparison of body weights between the $6^{\text {th }}$ generation of "Huanghai No.1" and unselected populations during their growth.

After seven generations of orientated selection, the new variety showed a somewhat different morphology from the wild population ( $\mathrm{Li}$ et al. 2006a). The length of the total abdominal section increased significantly and the total somites were longer while the widths of the carapace and the first somite were narrower. Compared to the wild population, the length of the $3 \mathrm{rd}$, 5th and 6th somites increased by $2.41 \%, 2.27 \%$ and $3.41 \%$, respectively, and the widths of carapace and the first somite were narrowed by $1.97 \%$ and $5.76 \%$, respectively. Based on statistical analysis, the morphological characteristics of "Huanghai No. 1" and the wild populations were significantly different. Two formulas were constructed to differentiate the morphology between "Huanghai No. 1" and the wild population, and the correct rate could reach 70.67\%. 
"Huanghai No. 1" : $Y=-371.7165+2334 x_{1}+3083 x_{2}+184.3125 x_{3}$

Wild populations : $Y=-387.2686+2248 x_{1}+3234 x_{2}+218.4082 x_{3}$

Where, $Y$ : the discriminant accuracy; $x_{1}$ : the length of third somite /body length; $x_{2}:$ the width of carapace / body length; $x_{3}:$ the width of first somite / body length.

\section{Genetic Characteristics}

In order to evaluate the genetic characteristics of "Huanghai No. 1", related research on genetic variation, genetic structure and growth-related molecular markers was conducted successively (He et al. 2007; Li et al. 2006b). A total of 240 RAPD primers were used to scan 150 shrimp individuals belonging to three groups: unselected populations (body length was between 11 and $14 \mathrm{~cm}$ ); big size group (body length was longer than $15 \mathrm{~cm}$ ) and small size group (body length was less than $15 \mathrm{~cm}$ ) of the sixth generation of "Huanghai No. 1". Two candidate molecular markers, one positively associated with growth and the other negatively associated with growth, were detected and validated, then designed as sequence characterized amplified regions (SCAR) markers (He et al. 2007). The results could be useful in molecular marker assisted selection (MAS) of F. chinensis in the near future.

Genetic variation and genetic structure of "Huanghai No. 1" were also analyzed. Results revealed that there was lower genetic difference within the selected variety $(G s t<0.05)$, which indicated that the genetic structure after seven successive generations of selection tends to stabilize (Li et al. 2006b).

\section{Commercial Farming of "Huanghai No.1"}

"Huanghai No. 1" had been recommended as the "Major Aquaculture Variety" by the Ministry of Agriculture of China since 2006. From 2006 to 2008, "Huanghai No.1" was cultured in more than 10,000 ha in Northern China, including Hebei, Shandong, Jiangsu and Liaoning provinces, and was widely accepted by shrimp farmers. Utilization of this improved variety in commercial farming practices showed at least a $20 \%$ increase in economic return.

\section{Selective Breeding on Disease Resistance -"Huanghai No. 2"}

Since 1998, arduous efforts were made to select a WSSV-resistant variety of $F$. chinensis. After 10 years of hard work, progress was achieved in selective breeding of disease resistant traits, and the new variety was named as "Huanghai No. 2". This new 
variety showed better survival rate after WSSV infection in the laboratory and at the farm. Furthermore, farming practice also proved its tolerance to unfavorable culture conditions.

\section{Breeding Scheme}

The breeding scheme of the disease-resistant variety "Huanghai No. 2" is presented in Fig. 3.

The selection began in 1998. Initial spawners were collected from ponds that were seriously infected with WSSV and the virus caused heavy shrimp mortality. The survivors were collected and used as candidates for the WSSV-resistant selection. In each of the following generations, a WSSV-challenge-test in the laboratory was applied to select the WSSV-resistant individuals (Kong et al. unpubl. data). Pilot scale farming practice showed that the survival rate increased by more than $30 \%$ via this individual selection compared with $0-30 \%$ survival rate of unselected ones. Since 2001, family selection was introduced and 3 5 families that showed higher survival rate after artificial WSSV infection of around 30 families were added into the base population. After 5 years' selection, a WSSV-resistant line of $F$. chinensis was produced and named as "Jikang 98" in 2003. Since 2005, "Huanghai No. 1" and other four distinct wild populations were introduced into the breeding program, and breeding value estimates of multi-traits using BLUP (Best Linear Unbiased Prediction) were employed. Based on an unbalanced nested design, about 100 families were produced each year in the Selective Breeding Centre, Yellow Sea Fisheries Research Institute, and the target traits were not only WSSV-resistance, but also faster growth and higher survival rates, with weighing values of $15 \%, 80 \%$ and $5 \%$, respectively. After three more generations of selection via BLUP, multi-traits breeding technology was set up and the new variety of F. chinensis named as "Huanghai No. 2" was developed in 2008. During the breeding of "Huanghai No. 2", the inbreeding coefficient was controlled to less than $1 \%$ in order to avoid inbreeding. 


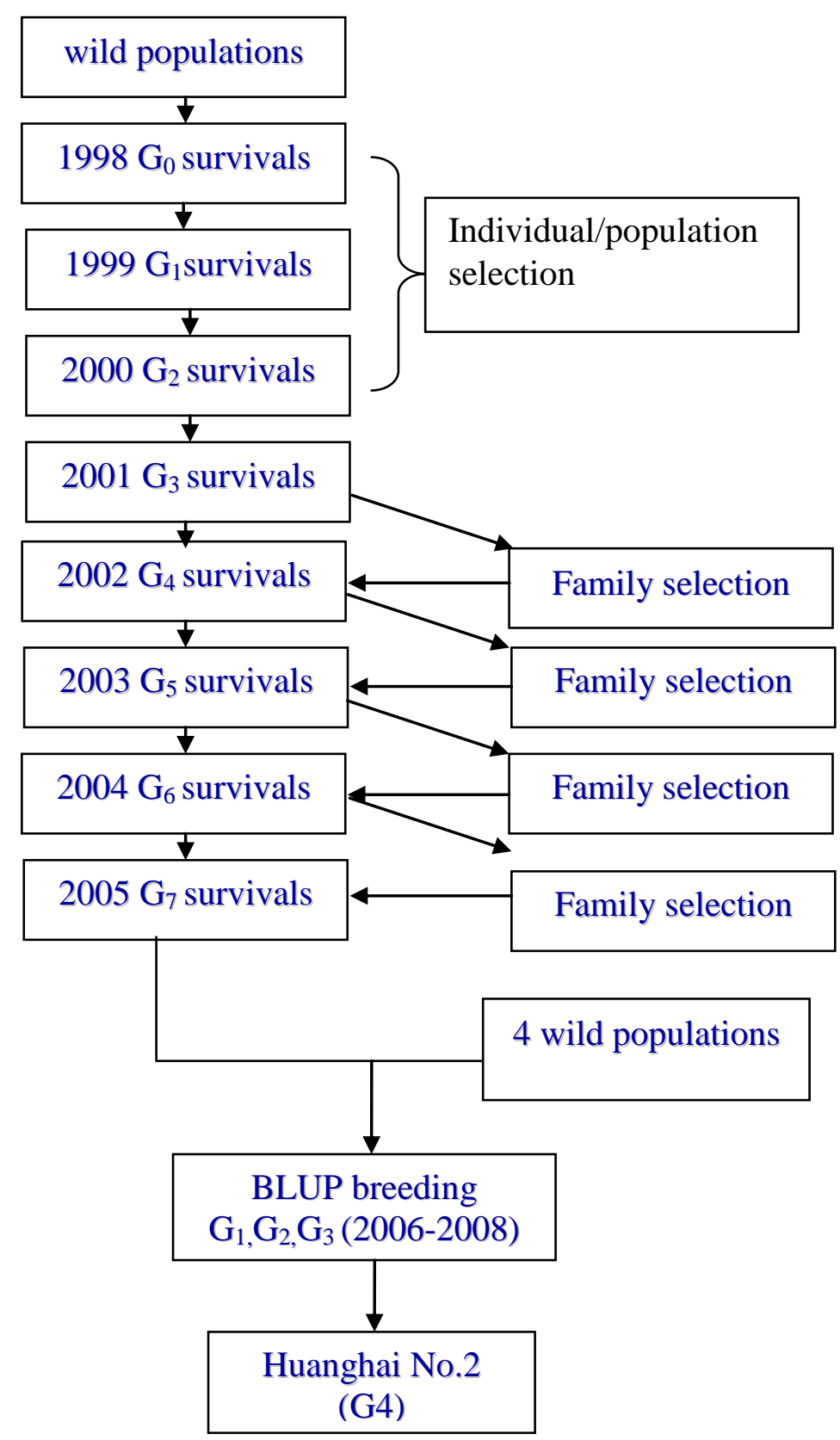

Fig. 3. Breeding scheme of "Huanghai No. 2"

\section{Performance and Genetic Gain of "Huanghai No. 2"}

The new variety Huanghai No. 2 was mainly characterized by a better WSSVresistance/tolerance, which means longer survival time and higher survival rate after 
artificial WSSV infection in the laboratory and in the field when compared with the unselected ones, as well as faster growth rate, which is preferred by farmers for producing bigger shrimp.

In order to evaluate the genetic gain of "Huanghai No.2", experiments were conducted to compare the main traits between the selected families (with higher breeding value among all families) and control families (with median breeding value among all families) under the same culture conditions during 2006-2008 (Zhang et al. 2008). Results showed that all the target traits have been improved to varied extents. The genetic gain of grow-out body weight, survival time post WSSV infection and grow-out survival rate was $13.56 \%, 6.67 \%$ and $5.05 \%$, respectively, after 3 years' selection (Table 2). Comparison on the performance of "Huanghai No. 2" and commercial shrimp were also made in 2008. The results showed that the superiority of "Huanghai No.2" in harvest body weight, survival time and survival rates was $35.85 \%$, $15.85 \%$ and $5.35 \%$, respectively. These data demonstrated that the breeding procedure of "Huanghai No. 2" was effective and feasible.

Table 2. The genetic gain of main traits of "Huanghai No. 2"

\begin{tabular}{llll}
\hline Genetic gain $(\%)$ & Body weight & Survival time $^{1}$ & Survival rate $^{2}$ \\
\hline 2006 & 12.23 & 4.15 & 3.49 \\
2007 & 15.56 & 6.38 & 5.40 \\
2008 & 12.91 & 9.74 & 6.26 \\
Mean & 13.56 & 6.76 & 5.05 \\
\hline Heritability $\left(h^{2}\right)^{3}$ & $0.22 \pm 0.16$ & $0.14 \pm 0.12$ & $0.03 \pm 0.021$ \\
\hline
\end{tabular}

Note: ${ }^{1}$ The genetic gain of survival time between selected and control families after artificial infection of WSSV;

${ }^{2}$ The genetic gain of survival rate between selected and control families when shrimp were harvested in experimental pond without WSSV infection;

${ }^{3}$ Heritability $\left(h^{2}\right)$ was estimated based on the data of 2008 .

\section{Pathogen Detection and Disease Control}

It was difficult to set up totally virus (WSSV) free conditions for $F$. chinensis larvae rearing in hatcheries, especially in the small-scale hatcheries. Several special measures were taken to reduce the risk of WSSV infection, which allowed shrimp larvae suppliers to offer larvae without a specific pathogen. All of these measures developed had been summarized technically and could be found from several domestic patents in China, for example, shrimp embryo disinfection of WSSV technique (Patent No. ZL01107747.6) and SPF shrimp larvae rearing technique (Patent No. ZL02135494.4). At the same time, a series of quick and accurate WSSV detection 
technologies had been set up. T-E staining technique could diagnose WSSV in 10 min (Huang et al. 1995a), the transmission route was revealed by ELISA with monoclonal antibody (Huang et al. 1995b), commercialized dot blot kit with gene probe and PCRgene probe technology (Lei et al. 2001) and LAMP technology (Patent No. ZL200810139949.4) were applied for large-scale investigation (Lei et al. 2001).

\section{Immuno-Enhancement Technology}

Like all crustaceans, $F$. chinensis lacks a full-evolutionary specific immune system. However, experiments had shown that by adding some special elements with biological activity into formulated feed, it was possible to increase shrimp's diseaseresistance/tolerance to a certain extent. The ongoing related research included the development of peptidoglycan as immuno-stimulant, the selection and utilization of probiotics for disease resistance and a combination of probiotics and bio-floc technology. Preparation of low molecular-weight peptidoglycan is accomplished by two-enzyme method, enhancement of phenoloxidase, alkaline phosphatase, hemocyte phagocytosis activities, etc. In farming practice, it was reported that adding $0.2 \%$ biological activity elements of peptidoglycan from $\mathrm{G}^{+}$bacteria to feed could increase the survival rate of farmed shrimp by $30 \%$ (Song et al. 2005).

\section{Farming Technological Innovation}

Tremendous efforts were made to explore the optimal approaches to sustainable shrimp farming in China in recent years. The principle of biosecurity was applied to the farming industry and field practices proved that the principle was applicable technically and both economic and ecological benefits could be achieved if the principle was properly implemented. The main techniques involved in shrimp farming practice include: stocking SPF larvae, adopting a limited water exchange system, using aerators properly, applying water quality improving reagents such as probiotics, properly using water quality management measures, adding additives to feeds to enhance anti-stress and immune abilities of shrimp, controlling pathogenic bacteria in farming ponds and properly managing the effluent from shrimp farming ponds. After years of gradual improvement, several farming modes were set up technically and used in the farming of F. chinensis.

\section{Deep-Pond-Farming Mode}

Farming ponds were built above the high tide zone along the coastal area. Typically, the ponds were $0.33 \sim 0.4$ ha in size and $2.5 \sim 3 \mathrm{~m}$ in depth. The pond bottom was built with a $0.2 \%$-slope to outlet, so discharged water can flow out easily. Waterproof materials were used to prevent collapsing and leaking of ponds, and 
farming water was pumped from an uncontaminated sea area. The stocking density of 7-day postlarvae $\left(\mathrm{PL}_{7}\right)$ ranged at 100 150 seed $\mathrm{m}^{-2}$ and SPF postlarvae were strongly recommended to be used to prevent introduction of shrimp virus. The limited water exchange system was applied and daily exchange ratio was kept at 5 10\%. High quality feeds (with additives to improve shrimp immunity and anti-stress) were used. WSSV and other pathogenic bacteria (i.e. Vibrio spp.), as well as feed and water quality was routinely monitored. Farming practices proved that the above measures when implemented collectively and properly could control the water quality and pathogenic agents within an acceptable level and achieve a good harvest. In Shandong Province, deep pond farming played an important role for Chinese shrimp farming (Li et al. 2003). Even though the costs to build such ponds were relatively high, their merit was evident, a yield of 8 15 ton ha $^{-1}$ per crop could be harvested.

\section{Indoor-Industrialized-Farming Mode}

Cement and/or fibreglass-reinforced plastic tanks were built indoor to facilitate farming activities such as stocking the larvae ahead of main culture season and postponing harvest in Northern China where natural conditions permit only one crop. The following characteristics define this mode: a) farming tanks are usually 50 200 $\mathrm{m}^{2}$ in size; b) shrimp were stocked at a higher density of 200 300 individual $\mathrm{m}^{-2}$; c) pure liquid oxygen was usually used; d) the farming yield in each crop was $2.5 \sim 4 \mathrm{~kg} \cdot \mathrm{m}^{-2}$; e) water exchange ratio daily was usually about $30 \%$; f) higher investment in facility, feed cost, energy supply, etc. Li et al. (2006) found that the quantity of phytoplankton, zooplankton and benthos were higher in semi-intensive farming ponds than in indoor industrialized farming tanks, but $\mathrm{DO}, \mathrm{NH}_{4}-\mathrm{N}$ and $\mathrm{PO}_{4}-\mathrm{P}$ concentrations were the opposite and the concentrations of $\mathrm{N}$ and $\mathrm{P}$ were seldom affected by the DO and the stocking density in industrialized shrimp culture system (Liu et al. 2008). Shrimp growth rate and survival rate in indoor industrialized farming tanks were lower than those in semi-intensive farming ponds, but indoor industrialized farming gained higher production yield because of the higher stocking density. This farming mode has obtained a higher success rate because it experienced limited influence from the weather and many farming factors were controlled artificially. As such it was practiced in the coastal areas in Northern China. Usually the shrimp harvested were smaller as a result of the higher stocking density, but the yield was higher in terms of per unit farming area.

\section{The Integrated Farming Mode}

The integrated farming mode (also termed polyculture, ecological culture, etc.) means several aquatic species (in most cases two or three species) were cultured in the same pond based on their feeding behavior and ecological adaptation. Usually different 
species of fishes, crabs, shellfishes and seaweeds are considered for farming with the appropriately-varied ratio (Wang et al. 2001; Liu and Li 2007). The purpose of this farming mode was to improve the efficiency of energy and feed, utilize the water body three-dimensionally, form a mutually beneficial ecological system among the culture species and consequentially increase the output per farming unit area. This system practically emphasizes a rational integration of farming species with different trophic levels, accelerating the circulation of matter and energy in a farming pond, making full use of the artificial and natural products such as nutrients, salts, dissoluble organic substances, particle organic matters, planktons, benthos, etc., to achieve optimum outputs. In most cases in Northern China, ponds practicing the integrated farming mode usually range from 2 to 20 ha in size with a water depth of 1.5 to $2 \mathrm{~m}$. This mode requires less investment and begins with a lower stocking density (15 20 shrimp postlarvae $\mathrm{m}^{-2}$ usually), and production yield could be as low as $750 \mathrm{~kg}^{\cdot} \mathrm{ha}^{-1}$, but this mode could also produce larger size shrimp which means much better market value. At the same time, lower stocking density means less feed, less labor, better water quality and most importantly, less impact to the environment.

\section{Discussions}

Traditional selective breeding based on phenotype has achieved remarkable progress in genetic improvement of $F$. chinensis especially on growth performance. However, there are still problems that the selective strategies have to address. For example, high-intensity selection could increase the probability of inbreeding if the relationship or genetic correlation among individual candidates was ignored in successive generations. Selective breeding strategies including BLUP genetic evaluation could not achieve ideal progress for traits that have low heritability such as WSSV-resistance of $F$. chinensis. Therefore, a long-term strategy should be established to breed the new varieties characterized by faster growth rate, stronger disease resistance /tolerance, better feed efficiency, etc. We believe that we have initiated such exploration with a good start but realize that more challenges still lie ahead. At the same time, a healthy shrimp farming approach is strongly recommended for sustainable development which includes high-health seed rearing, water quality management, probiotics application, high quality feed and optimal feeding regime, organic waste biodegradation, pathogen diagnosis and integrated disease control, effluent management, etc. Some suggestions for further research are presented below:

\section{a) Establishing and optimizing the technical approaches of new variety breeding and} extension: To evaluate the farming performance and economic benefits of a genetically improved variety, an optimized and traceable management system should be established by which the possible gene or genetic contamination could be avoided. Moreover, this 
type of system would be helpful to accelerate the genetic gain of shrimp by screening candidate brooders with molecular markers that associate with commercially important traits especially growth performance and disease resistance. Research on SNP (Single Nucleotide Polymorphism) and genomics of $F$. chinensis are expected to contribute more knowledge at the molecular level.

\section{b) Extending the limited water exchange system and bio-security concepts to shrimp} farming: With the advancement of technology, it is acceptable to apply limited water exchange system in large-scale shrimp farming. Enclosed farming systems permit recirculation of a large proportion of sea water during the growout season and enable the shrimp farms be kept relatively isolated, which can prevent pathogen transmission from external sources and reduce potential cross-contamination within the system.

c) Enforcing standardization of shrimp farming activities, and establishing and refining related regulations and laws: A responsible shrimp farming industry means not only producing sufficient quantity of shrimp to meet the needs of a continuously expanding market, but also high quality shrimp products to satisfy consumers. By enforcing the related regulations and/or laws, it will help to standardize the mariculture activities and essentially protect the shrimp farming industry from deviating from the way of sustainable development.

d) Developing an ecosystem approach for shrimp farming: In farming areas where social and/or economic conditions are not suitable for developing industrialized shrimp farming, ecosystem-based or integrated shrimp farming mode could make full use of farming resources and garner an ideal economic return.

\section{Acknowledgements}

This project is supported by the National Hi-Tech R\&D Program (Grant No. 2006AA10A406; 2010AA10A401), National Key Technology R\&D Program (Grant No. 2006BAD01A13), Special Project of Public Service Industry (Grant No. nyhyzx07042) and China Modern Agriculture Research System (Grant No. CARS-47).

\section{References}

Carr, W., J. Sweeney and J. Swingle. 1994. The Oceanic Institute's SPF shrimp breeding program status, pp. 47-54. US Marine Shrimp Farming 10th Anniversary Review, GCRL Special Publication.

Deng, J.Y. 1997. Studies on release enhancement of Penneid shrimp. Marine Fisheries 1:1 (in Chinese). 
Deng, J.Y. and C.C. Ye. 2001. Science of Fishery Resources, pp. 295-309. Chongqing Press, Chongqing. (in Chinese).

Deng, J.Y., C.C. Ye and Y.C. Liu. 1990. Shrimp in Bohai Sea and Yellow Seas and its resource management. Ocean Publishing House, Beijing. 283 pp. (in Chinese).

He, Y.Y., P. Liu, J. Li, J. Kong and Q.Y. Wang. 2004. Analysis of genetic structure in the first cultured stock and the sixth cultured stock of Fenneropenaeus chinensis. Journal of Fishery Science of China 11(6):572-575(in Chinese).

He, Y.Y., P. Liu, J. Li and Q.Y. Wang. 2007. Growth traits related SCAR markers in Fenneropenaeus chinensis, Oceanologia et Limnologia Sinica 38(1):42-48.

Huang, J. and J. Yu. 1995a. A new staining method for on-site observation of viral inclusion bodies of penaeid shrimp. Marine Fisheries Research 16(1):31-37 (in Chinese).

Huang, J., J. Yu, X.H. Wang, X.L. Song, C.S. Ma, F.Z. Zhao and C.H. Yang. 1995b. Survey on the pathogen and route of transmission of baculoviral hypodermal and hematopoetic necrosis in shrimp by ELISA of monoclone antibody. Marine Fisheries Research 16(1):45-50 (in Chinese).

Huang, J., X.L. Song, J. Yu, C.H. Yang. 1995c. Baculoviral hypodermal and hematopoietic necrosis -- study on the pathogen and pathology of the explosive epidemic disease of shrimp. Marine Fisheries Research, 16(1): 1-10. (in Chinese, with English abstract)

Lei, Z.W., C.Y. Shi, J. Huang, B. Yang, K.K. Yu and W.B. Zhan. 2001. Development of digoxigenia labeled probe for detection of White Spot Syndrome by dot-blot hybridization. Journal of Ocean University of Qingdao 31:201-204 (in Chinese).

Li, J., P. Liu, Y.Y. He, Q.S. Song, N.N. Mu and Q.Y. Wang. 2005. Artificial selection in the new breed of Fenneropenaeus chinensis named "Yellow Sea No. 1" based on fast growth trait. Journal of Fisheries of China 29:1-5 (in Chinese).

Li, J., C.S. Ma, X.N. Li, D.Y. Liu and Z.Y. Liu. 2003. Study on shrimp culture model in deep pond and high dam. Marine Sciences 27(7):1-4.

Li, Z.X., J. Li, Q.Y. Wang, Y.Y. He and P. Liu. 2006b. The effects of selective breeding on the genetic structure of shrimp Fenneropenaeus chinensis populations. Aquaculture 258:278-282.

Li, Z.X., J. Li, Q.Y.Wang, Y.Y. He and P. Liu. 2006a. The comparison of morphological characteristics in selected new variety "Huanghai No. 1" and the wild population of shrimp Fenneropenaeus chinensis. Journal of Fisheries of China 13:384-388 (in Chinese).

Li, Y.Q., J. Li, Q.Y. Wang and D.Y. Liu. 2006. Analysis on structure and benefit of superintensive and semi-intensive shrimp farming systems. Marine Fisheries Research 27(5):85-90 (in Chinese).

Liu, B., Q.Y. Wang, J. Li, P. Liu and Y.Y. He. 2010. A genetic linkage map of the marine shrimp Penaeus (Fenneropenaeus) chinensis based on AFLP, SSR, and RAPD markers. Chinese Journal of Oceanology and Limnology 28:1-11.

Liu, G.L. and X.F. Li. 2007. Study on polyculture of Portunus trituberculatus with Chinese shrimp named "Huanghai No. 1". Scientific Fish Farming 12:38.

Liu, J., K.M. Qu, H.Y. Liu, J.X. Zhu, J. Li and D.L. Ma. 2008. Studies on features of water environment in industrialized shrimp culture system. Marine Fisheries Research 29(6):1-8.

Lo, C.F., C.H. Ho, S.E. Peng, C.H. Chen, H.C. Hsu, Y.L. Chiu, C.F. Chang, K.F. Liu, M.S. Su, C.H. Wang and G.H. Kou. 1996. White spot syndrome baculovirus (WSBV) detected in 
cultured and captured shrimp, crabs and other arthropods. Diseases of Aquatic Organisms 27:215-225.

Pruder, G.D., C.L. Brown, J.N. Sweeney and W.H. Carr. 1995. High health shrimp systems: seed supply - theory and practice. In: Swimming through troubled waters. Proceedings of Special Session on Shrimp Farming, Aquaculture '95. 1-4 February, 1995, San Diego. (ed, C.L. Browdy and J.S. Hopkins), pp. 40-52. World Aquaculture Society, Baton Rouge, LA, USA.

Song, X.L., X.H. Wang, G.F. Chen, J. Zhou and L. Liu. 2005. Studies on anti-infectivity to White Spot Syndrome Virus of Penaeus vannamei by oral peptidoglycan preparation. High Technology Letters 15(1):74-78 (in Chinese).

Wang, J.Q., D.S. Li, S.L. Dong, K.X. Wang and X.L. Tian. 2001. Intensive polyculture of sea perch with Chinese shrimp and red Taiwanese tilapia hybrids. Journal of Fishery Sciences of China 7:37-41.

Wang, Q.Y., Z.M. Zhuang, J.Y. Deng and Y.M. Ye. 2006. Stock enhancement and translocation of the shrimp Penaeus chinensis in China. Fisheries Research 80:67-79.

Wang, Q.Y., C.H. Yang and J. Yu. 1995. The shrimp farming industry in China: past development, present status and perspectives on the future. In: Swimming through troubled waters. Proceedings of Special Session on Shrimp Farming, Aquaculture '95. 1-4 February, 1995, San Diego. (ed, C.L. Browdy and J.S. Hopkins), pp. 1-12. World Aquaculture Society, Baton Rouge, LA, USA.

Wyban, J.A., J.S. Swingle, J.N. Sweeney and G.D. Pruder. 1995. Specific pathogen-free Penaeus vannamei. World Aquaculture 24:39-45.

Yan, D.C., S.L. Dong, J. Huang, J.Z. Zhang. 2007. White spot syndrome virus (WSSV) transmission from rotifer inoculum to crayfish. J Invert. Pathol, 94: 144-148.

Zhang, J.S., S.L. Dong, X.L. Tian, Y.W. Dong, X.Y. Liu and D.C. Yan. 2006. Studies on the rotifer (Brachionus urceus Linnaeus, 1758) as a vector in white spot syndrome virus (WSSV) transmission. Aquaculture 261:1181-1185.

Zhang, T.S., J. Kong, S. Luan, K. Luo, Q.W. Zhang, H.L. Hu, X.M. Sun and Q.Y. Wang. 2008. Genetic gain for one generation BLUP selection of Chinese shrimp (Fennropenneus chinensis). Marine Fisheries Research 29(3):35-40 (in Chinese).

Zhang, T.S., Q.Y. Wang, P. Liu, J. Li and J. Kong. 2005. Genetic diversity analysis on selected populations of shrimp Fenneropenaeus chinensis by microsatellites. Oceanologia Et Limnologia Sinica 36(1):72-80. 